Patients 35 CH-C genotype 1 patients (23 males, median age 37 years) treated with Peg-IFN/ribavirin were divided in two groups: 18 responders (SVR), 17 non-SVR (nine non-responders and eight relapsers).

Methods rs12979860 and rs8099917 were tested by direct sequencing. Baseline numbers of $\mathrm{NK}$ cells $\left(\mathrm{CD}^{-} \mathrm{CD}^{-} 6^{+}\right)$, their subsets $\mathrm{CD} 56^{\mathrm{dim}} / \mathrm{CD} 56^{\text {bright }}, \mathrm{CD}^{-} \mathrm{CD}^{-} 6^{ \pm} \mathrm{CD} 16^{ \pm}$, and expression of NK cells activation/inhibition (NKG2D/NKG2A) markers were investigated by flowcytometry on peripheral blood mononuclear cells (PBMC). PBMC IFN- $\gamma / \mathrm{IL}-10$ production after exposure to HCV antigens was evaluated by intracellular cytokine staining. Results are presented as medians.

Results Rs12979860 genotype CC was more frequent in SVR than non-SVR ( $85 \%$ vs 15\%), while non-CC genotypes (CT/TT) were present in $32 \%$ SVR vs $68 \%$ non-SVR. $75 \%$ SVR had TT genotype for rs 8099917 vs $25 \%$ non-SVR and non-TT genotypes (GT/GG) were more frequent in non-SVR then SVR ( $80 \%$ vs $20 \%$, all pbright subset was higher in SVR than non-SVR (6.4\% vs $2.9 \%, \mathrm{p}=0.03)$. $\mathrm{CD}^{-}{ }^{-} \mathrm{CD} 56^{-} \mathrm{CD} 16^{+}$cells subset was more frequent in non-SVR than SVR (11.4\% vs $8.6 \%, \mathrm{p}=0.05)$. The proportion of $\mathrm{CD}^{\mathrm{dim}+} /$ $\mathrm{NKG}_{2} \mathrm{D}^{+}$cells was higher in SVR than non-SVR (47.1\% vs $36.3 \%$, $\mathrm{p}=0.04)$. While number of $\mathrm{CD} 4+\mathrm{HCV}$ core-specific IFN- $\gamma$ producing cells was similar in all groups, the frequency of HCV corespecific CD4+ cells producing IL-10 was higher in non-SVR than SVR $(4.3 \%$ vs $1.8 \%, p=0.05)$. Comparing patients according to rs12979860 CC vs no CC genotypes, CC genotype patients had more CD56 bright cells $(6.6 \%$ vs $3.1 \%, p=0.04)$, fewer $\mathrm{CD}^{-} \mathrm{CD}^{-} 6^{-} \mathrm{CD} 16^{+} \mathrm{NK}$ cells $(8.7 \%$ vs $11.1 \%, \mathrm{p}=0.05)$ and fewer $\mathrm{HCV}$-core specific $\mathrm{CD}^{+} / \mathrm{IL}-10^{+}$cells $(1.9 \%$ vs $4.2 \%, \mathrm{p}=0.05)$. There were no associations between rs8099917 genotypes TT vs no TT and innate or adaptive immune responses in this cohort.

Conclusion High numbers of CD56 $6^{\text {bright }}$ NK cells, low numbers of unconventional $\mathrm{CD}^{-} \mathrm{CD}^{-} 6^{-} \mathrm{CD} 16^{+} \mathrm{NK}$ cells, and low HCVspecific IL-10 production at baseline are associated with IL28B gene SNP rs12979860 CC genotype and successful antiviral treatment of $\mathrm{CH}-\mathrm{C}$ genotype 1.

Competing interests None declared.

\section{PM0-159 ETHNIC ORIGIN AND VARIATION IN OUTCOME IN PATIENTS WITH HEPATOCELLULAR CARCINOMA AND HEPATITIS B INFECTION}

doi:10.1136/gutjnl-2012-302514b.159

J R L Maggs, * M A Heneghan, N Heaton, J G O’Grady, K Agarwal, A R Suddle. Institute of Liver Studies, King's College Hospital, London, UK

Introduction Hepatocellular carcinoma (HCC) is a major cause cancer-related mortality, world wide. In particular, HCC is associated with chronic hepatitis B infection (CHB) in Africa and South East Asia. Most published data relating to the natural history of $\mathrm{CHB}$ and $\mathrm{HCC}$ originates from South East Asia; however due to differences in HBV genotype and potential environmental and genetic factors, it is not clear whether this data are applicable to the African population. Therefore, to explore this issue we have compared the characteristics and outcomes of patients with $\mathrm{CHB}$ and HCC according to ethnic origin.

Methods Patients with HCC complicating $\mathrm{CHB}$, managed at King's College Hospital London, were identified from our clinic databases. Demographic information, laboratory parameters, initial tumour staging and outcome data, including HBe-antigen status, viral load and genotype, were collated where available. Comparison was performed between Black patients and patients of South East Asian origin.
Results In total, 295 patients with HCC and CHB were identified. Median age at the diagnosis of tumour was 37 years and $85 \%$ of patients were male. Ethnicity was classified as Black in $27 \%$ of patients and South East Asian in 21\% of these patients. Cirrhosis was present in $81 \%$ whereas $8 \%$ were non-cirrhotic at diagnosis of HCC; data were unavailable in the remaining $11 \%$ of patients. $18 \%$ were $\mathrm{HBe}$-antigen positive and $7 \%$ hepatitis $\mathrm{C}$ antibody positive. The distribution of HBV genotypes varied according to ethnic group, with genotypes $\mathrm{A}$ and $\mathrm{E}$ restricted to Black patients and genotypes B and C to South East Asian patients. On comparing these two groups, there were no differences in gender, the presence of cirrhosis, co-factors for liver disease, laboratory parameters or tumour stage, as assessed by the BCLC staging system. However, Black patients were significantly younger (median age: 44 vs 61 years, $p<0.001)$. Although not significant, there was a trend towards a greater frequency of $\mathrm{HBe}$-antigen positivity in the Black patients. No difference in viral load was observed. There was an increased probability of death within the follow-up period in the Black group ( $66 \%$ vs $39 \%, p=0.004)$. Comparison of Kaplan-Meier survival curves for the two groups demonstrated decreased survival following diagnosis of HCC in the Black group (log rank: $\mathrm{p}=0.31$ ).

Conclusion In our cohort, we have observed that Black patients present at a younger age and have poorer length of survival in comparison to South East Asian patients. This may represent a more aggressive HCC phenotype that is associated with HBV genotypes $\mathrm{A}$ and $\mathrm{E}$ although there are potentially multiple confounding factors. Further research is required to determine the cause of this apparent inequality.

Competing interests None declared.

\section{PMO-160 LIVER TRANSPLANTATION FOR CHRONIC HEPATITIS C IN NORTHERN IRELAND}

doi:10.1136/gutjnl-2012-302514b.160

${ }^{1} \mathrm{~J}$ Addley, ${ }^{*}{ }^{1} \mathrm{~N}$ McDougall, ${ }^{1} \mathrm{I}$ Cadden, ${ }^{1} \mathrm{~J}$ Cash, ${ }^{2} \mathrm{~J}$ O'Grady. ${ }^{1}$ Liver Unit, Royal Victoria Hospital, Belfast, UK; ${ }^{2}$ Liver Unit, King's College Hospital, London, UK

Introduction Chronic hepatitis $\mathrm{C}(\mathrm{CHC})$ is a leading cause of chronic liver disease in the UK. Orthotopic liver transplantation (OLT) is commonly used for end stage cirrhosis or hepatocellular cancer secondary to $\mathrm{CHC}$. Unfortunately recurrence of $\mathrm{CHC}$ in the graft of transplant recipients is almost universal, often leading to accelerated liver damage. Our aim was to assess the outcome of patients attending a Regional Liver Unit in Northern Ireland who underwent OLT for liver disease due to $\mathrm{CHC}$.

Methods A retrospective study was carried out of patients from Northern Ireland who had OLT between 1998 and 2010 for CHC associated chronic liver disease. Cases were identified by review of the regional OLT database and cross-referenced with the centre where OLT was carried out (KCH, London).

Results Sixteen patients (11 male) underwent 20 OLTs for CHC between April 1998 and December 2010 (<10\% of all OLTs). Mean age was 54 years. 13 patients had single OLT and 3 required multiple transplants. The HCV genotypes were 1 (7), 3 (5) and 2 (4). Prior to OLT, 10 patients received antiviral therapy-all failed (five nonresponders, two relapsed following treatment and three failed to tolerate treatment). Data were only available on 19 OLT episodes. Immunosuppressant maintenance therapy was as follows: tacrolimus (9), tacrolimus + mycophenolate (4), cyclosporine (1) and mycophenolate + prednisolone (1). Short-term complications included acute cellular rejection in 5 (26.3\%) requiring pulsed methylprednisolone (4) or IL2 blockade (1). Two patients developed 
renal failure requiring short-term dialysis post transplantation. Long-term complications included biliary anastomotic stricture in 6 (31\%) patients and vascular complications in 3 (2 hepatic artery thrombus, 1 hepatic vein stenting). One patient acquired hepatitis B from the transplanted liver. Reasons for re-transplantation were hepatic artery thrombosis (2), recurrent cirrhosis with portal hypertension (1) and primary non-function of the graft (1). Seven (35\%) transplants had cirrhosis confirmed on biopsy (5) or clinically (ascites (1) or oesophageal varices (1)) at a mean time of 25.6 months post transplant (range 12-48 months). Five-year mortality in the cohort was $25 \%$.

Conclusion Hepatitis C accounted for $<10 \%$ of OLT episodes in Northern Ireland during the study period. This demand may increase in the future as the chronic complications of previously undiagnosed hepatitis $\mathrm{C}$ are seen. One third of this small cohort developed cirrhosis within a few years of OLT.

Competing interests None declared.

\section{PM0-161 HEPATITIS E (HEV) IN SOUTH WEST ENGLAND. GEOGRAPHICAL, ENVIRONMENTAL AND SOCIAL FACTORS: A CASE CONTROL STUDY}

doi:10.1136/gutjnl-2012-302514b.161

\begin{abstract}
1,2 J Hunter, ${ }^{* 1} \mathrm{R}$ Madden, ${ }^{1} \mathrm{~A}$ Stone, ${ }^{1} \mathrm{~N}$ Osborne, ${ }^{1} \mathrm{~B}$ Wheeler, ${ }^{3} \mathrm{M}$ Barlow, ${ }^{1} \mathrm{R}$ Bendall, ${ }^{4} \mathrm{~N}$ Lin, ${ }^{4} \mathrm{~W}$ Henley, ${ }^{1} \mathrm{~W}$ Gaze, ${ }^{1} \mathrm{H}$ Dalton. ${ }^{1}$ European Centre for Environment \& Human Health, Peninsula College of Medicine and Dentistry; ${ }^{2}$ Universities of Exeter and Plymouth, Truro; ${ }^{3}$ Health Protection Agency, St Austell; ${ }^{4}$ Centre for Health and Environmental Statistics, University of Plymouth, Plymouth, UK
\end{abstract}

Introduction $\mathrm{HEV}$ is an emerging infection in developed countries, and is considered a porcine zoonosis. HEV has been found in pigs world wide and a number of water courses. In most cases the route of infection remains uncertain. A previous UK study showed that HEV was associated geographically to pig farms and coastal areas. ${ }^{1}$ AIM: To study the geographical, environmental and social factors in HEV infection.

Methods Cases of HEV and controls were identified from 2147 consecutive patients attending the Jaundice Hotline clinic, Cornwall (1999-2011). For each case and control the following were recorded: home postcode, distance from home to nearest pig farm, distance from home to coast, rainfall levels during the 8 weeks prior to presentation and socioeconomic status. A further 611 Cornish residents were tested for anti-HEV IgG to determine geographic differences in HEV seroprevalence.

Results 40 cases of HEV were identified. Seven were excluded from study as they contracted HEV outside Cornwall. 132 age/sex match controls were identified. 20/33 HEV cases clustered in the west of Cornwall, indicating that the geographical distribution was not uniform $(\mathrm{OR}=2.7,95 \% \mathrm{CI} 1.1$ to $6.5, \mathrm{p}=0.023)$. The seroprevalence of anti-HEV IgG in 611 Cornish residents increased gradually with age, and after adjusting for age/sex, there was no difference in seroprevalence between west Cornwall and the remaining study area. There was no difference between cases and controls in distance from the nearest pig farm, socioeconomic status or rainfall during the 8 weeks preceding disease presentation. Cases were more likely to live within $2000 \mathrm{~m}$ from the coast $(\mathrm{OR}=2.78,95 \%$ CI 1.20 to 6.67, $\mathrm{p}=0.02$ ), and this association remained significant after adjusting for age, sex, urban/rural domicile, proximity to pig farms and socioeconomic status.

Conclusion Cases of HEV are not uniformly distributed in Cornwall and cluster in the west of the county. This is not due to increased exposure to HEV at population level as there was no difference in HEV seroprevalence in the west of Cornwall and the rest of the study area. Proximity to a pig farm does not appear to be a risk factor for contracting HEV. Living within $2000 \mathrm{~m}$ of the coast does appear to be a risk factor, but the reason for this is uncertain.

Competing interests None declared.

\section{REFERENCE}

1. Ijaz $\mathbf{S}$ et al. J Infect Dis 2005;192:166-72.

\section{PMO-162 PREGNANT MOTHERS WITH CHRONIC HEPATITIS B (HBV): HOW OFTEN IS TREATMENT NEEDED?}

doi:10.1136/gutjnl-2012-302514b.162

${ }^{1} \mathrm{~J}$ Dyson, ${ }^{*}{ }^{2} \mathrm{E}$ Michael, ${ }^{2} \mathrm{~A}$ Turley, ${ }^{3} \mathrm{~S}$ Moses, ${ }^{3} \mathrm{M}$ Valappil, ${ }^{4,5} \mathrm{M}$ Hudson, ${ }^{4,5} \mathrm{M}$ Bassendine, ${ }^{4,5} \mathrm{~S}$ McPherson. ${ }^{1}$ Northern Deanery, Newcastle University, Newcastle, UK; ${ }^{2}$ Obstetrics, Newcastle upon Tyne NHS Trust, Newcastle University, Newcastle, UK; ${ }^{3} H P A$, Newcastle University, Newcastle, UK; ${ }^{4}$ Liver Unit, Freeman Hospital, Newcastle University, Newcastle, UK; ${ }^{5}$ Institute of Cellular Medicine, Newcastle University, Newcastle, UK

Introduction HBV is a common cause of chronic liver disease worldwide. Vertical transmission is the commonest mode of infection. Since 2000 antenatal HBV screening is offered to all pregnant women in the UK. The British Viral Hepatitis Group recommend treating mothers with an HBV DNA level of $>10^{7} \mathrm{IU} / \mathrm{ml}$ with antivirals in the 3rd trimester to reduce the transmission risk. Few studies have evaluated the epidemiology/management of pregnant patients with $\mathrm{HBV}$ in the UK. We reviewed the management of mothers with HBV attending our obstetric services.

Methods Retrospective notes review of all HBV positive mothers who attended the obstetric service from January 07 to November 11. Data were collected on patient demographics, viral serology, HBV DNA and ALT levels and HBV management during their first pregnancy in the time period.

Results $81 \mathrm{HBsAg}$ positive mothers (median age 28, 18-44) had 113 pregnancies in the study period. $96 \%$ were referred to the viral hepatitis service; however $28 \%$ of women did not attend $>1$ appointment. The mothers were born in 28 countries, most commonly China (30\%) followed by countries in Eastern Europe (17\%), Africa (16\%), South Asia (16\%) and elsewhere (21\%). $29 \%$ were known to have chronic HBV (cHBV). All mothers were tested for $\mathrm{HBeAg} / \mathrm{Ab}$ status: $15 \%$ were $\mathrm{HBeAg}$ positive, $85 \% \mathrm{HBeAg}$ negative and $79 \%$ anti-HBe positive. $85 \%$ had HBV DNA checked during the pregnancy. $9 \%$ had active $\mathrm{HBeAg}$ positive cHBV (HBV DNA > $20000 \mathrm{IU} / \mathrm{ml}$, ALT >40), 3\% had active HBeAg negative cHBV (HBV DNA > 2000 and ALT >40), 9\% were immunotolerant (HBeAg positive, ALT <40), 60\% were inactive carriers (HBV DNA $<2000$ and ALT $<40$ ) and $19 \%$ were indeterminate. $13 \%$ of mothers had a HBV DNA $>10^{7} \mathrm{IU} / \mathrm{ml}$, but only two patients were treated with tenofovir in the 3rd trimester. Of the eight patients with active HBV, six were successfully treated post-partum with oral antivirals/PEG-Interferon and two became inactive. $20 \%$ of inactive carriers experienced a post-partum flare in ALT that settled spontaneously.

Conclusion A high proportion of $\mathrm{HBV}$ infected mothers were born overseas; $>1$ in 6 had active cHBV or HBV DNA $>10^{7} \mathrm{IU} / \mathrm{ml}$ and were eligible for treatment to reduce the vertical transmission risk and/or prevent disease progression. All HBV infected mothers should be assessed for treatment and efforts to improve attendance at clinic appointments need to be intensified.

Competing interests None declared. 